\title{
Damage assessment and retrofitting of Marchesale Castle (San Giuliano di Puglia)
}

\author{
R. Cami ${ }^{1}$, C. Alessandri ${ }^{2}$, M. Indirli ${ }^{3} \&$ A. Tralli ${ }^{1}$ \\ ${ }^{1}$ University of Ferrara, Department of Engineering, Italy \\ ${ }^{2}$ University of Ferrara, Department of Architecture, Italy \\ ${ }^{3}$ ENEA, Bologna, Italy
}

\begin{abstract}
After the earthquake that struck the Molise Region (Italy), some ENEA researchers were involved in several post-seismic activities in San Giuliano di Puglia. Ancient and notable masonry cultural heritage structures (MCUHESs) suffered severe damage or partial collapse, including the old Marchesale Castle. This paper deals with a repairing proposal of the building, developed in the framework of a $\mathrm{PhD}$ thesis, elaborating diagnostics and dynamic campaigns results, providing numerical calculations and suggesting interventions in agreement with the existing code. Its main purpose is to enhance the building's seismic performance, avoiding conflicts between conservation and safety.

Keywords: seismic behaviour and vibrations, assessment and retrofitting.
\end{abstract}

\section{Introduction}

\subsection{A brief information on the seismic event occurred on October $31^{\text {st }}, 2002$}

A moderate earthquake struck Molise (Italy) on October $31^{\text {st }}, 2002$. The first shock (M 5.4) was followed by another (M 5.3) on the following day. Spread damage was evident in San Giuliano di Puglia, a small town located $5 \mathrm{~km}$ from the epicenter. The maximum Intensity at the site was estimated to be VIII-IX MCS, observed during both the 1456 and the 2002 events. The damage was not uniformly distributed inside San Giuliano narrow area, characterized by different levels of seismic hazard and structural vulnerability. ENEA experts took part in these activities following the seismic event: a) the emergency, under the coordination of the Civil Defense; b) the post-emergency, carrying out a detailed 
evaluation of damage, drafting the demolition plan, ensuring safe conditions to the buildings to be repaired, and operating for allowing residents to safely reenter their non-damaged houses; c) the reconstruction plan of San Giuliano; d) the technical-scientific advice to the Office of the Public Works Ministry for reconstruction and rehabilitation projects, including Marchesale Castle [10-12].

\subsection{Seismic input}

Before the earthquake, San Giuliano was not classified as a seismic zone, but subsequently it has been included in zone 2 (maximum Peak Ground Acceleration, PGA, equal to $0.25 \mathrm{~g}$ ) in the seismic reclassification of Italy [16]. The Civil Defense appointed a technical commission to provide the seismic microzoning of San Giuliano. The study reflects zones with different geology, topography and seismic local amplification. The 1456 earthquake (M 6.6, MCS XI) hit a large area of South-Central Italy; the event probably consisted in a long series of shocks, due to the simultaneous activation of several seismic sources, overlapping at least three areas encircling different epicenters [10-12].

\subsection{Structural vulnerability of the San Giuliano historical center}

The medieval center (fig. 1), interesting from an historical and architectural point of view, was deeply investigated. Despite the low local seismic amplification, it presented medium-severe damage and partial collapses. The Marchesale Castle (fig. 2) suffered heavy damage as well. All the area was generally characterized by high vulnerability and the most usual collapse mechanisms were wall failure with typical cross cracks but also out-of-plane overturning [10-12].

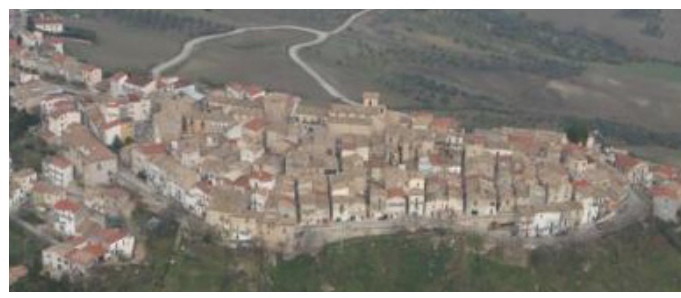

Figure 1: $\quad$ San Giuliano historical center. Figure 2:

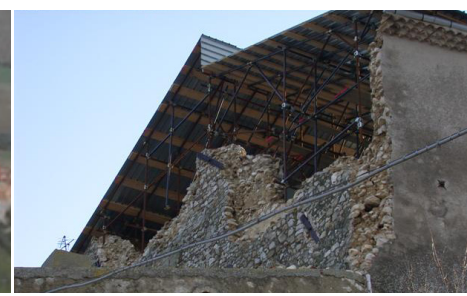

Damage to the castle.

\subsection{Design codes and requirements}

In many scientific studies, it is well-established that antiseismic interventions on MCUHESs located in seismic areas must harmonize protection and conservation [8-9], learning from periodical earthquake lessons [6-7]. Furthermore, the new Italian seismic code [16] and the related guidelines for cultural heritage [17] contain specific requirements to follow. In the authors' opinion, the approach to MCUHESs structural improvement can be summarized in the following statements: a) since repair is much more difficult to be faced than that related to modern r.c. or steel structures, interventions can derogate from the antiseismic 
design criteria foreseen for ordinary buildings; b) in relation to the state limit analysis, interventions must be defined as a "controlled structural improvement", i.e. accepting an antiseismic protection level lower than required, reducing invasivity; at the same time, great attention must be dedicated to the building final destination, in order to manage with accuracy the "Importance Factor" used in seismic standards (higher for public and strategic constructions [13]); c) the improvement effectiveness must be quantified, evaluating PGA levels generating local collapse mechanisms; d) detailed surveys and investigation campaigns are mandatory for MCUHESs, whose characteristics are frequently not well known; e) it is necessary to undertake the rehabilitation design in a specific way, since the use of standardized procedures is not possible; f) the observance of the "regola dell'arte", i.e. unwritten construction rules for masonry elaborated by architects and bricklayers in centuries of work practice, is fundamental for protection, conservation and restoration; g) the use of modern techniques and materials can be very useful to reduce seismic vulnerability, but it must be philologically correct, compatible and mechanically effective.

\section{Description of Marchesale Castle}

Historical information on Marchesale Castle (typical example of Southern Italian architecture) is very scarce. Around the first millennium A.D. a fortress with three towered doors was already built. The 1456 earthquake destroyed most of the medieval center, then reconstructed. Until present times, inhomogeneous works stratified, so that to diversify reworked parts from almost untouched ones. The castle consists in several blocks interconnected together; taking as reference the internal court ground, 4 upper and 3 lower levels envelope the hill slope (fig. 3). Multi-leaf stone-masonry walls are characterized by poor materials, irregular morphology and voids presence (concentrated in a loose internal core), with undoubted structural problems (internal layer weakness, mortar deterioration in the external joints, lacking of connections among external leaves). Therefore, the building is sensitive to "brittle" collapse mechanisms, both under vertical and horizontal loads, by layers detachment and out-of-plane expulsions. The tower (fig. 4) represents the most precious element of the entire complex. It is a squared-plan building, with buttresses on the West side and a Southern entrance portal (with a barrel vault) to the internal court. Most of the castle horizontal structures are generally wooden or steel-tied floors. Original stone vaults, with different geometries, can be found. The tower thick basement $(2.90 \mathrm{~m})$ shows pronounced tapering with height until $1.20 \mathrm{~m}$, and irregular masonry fabric in the façades, made by heterogeneous materials (mainly corner squared stones, variously sized river pebbles and brick insertions), likewise the majority of the castle walls. In the tower front it is still possible to identify pretty genuine architectonic evidences, the so called "buche pontaie" (small holes used to provide supplemental defense wooden scaffoldings) and the twice-line triangular pigeon houses located under the roof. Other aspects are: generally deteriorated mortar courses, plaster traces, brick fillings of old openings. After the seismic event, the tower top was tied up with steel cables and covered with a steel sheet. 

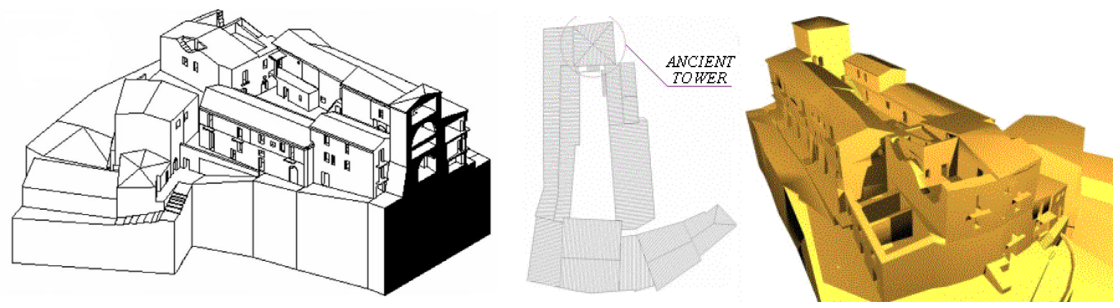

Figure 3: Geometry of Marchesale Castle.
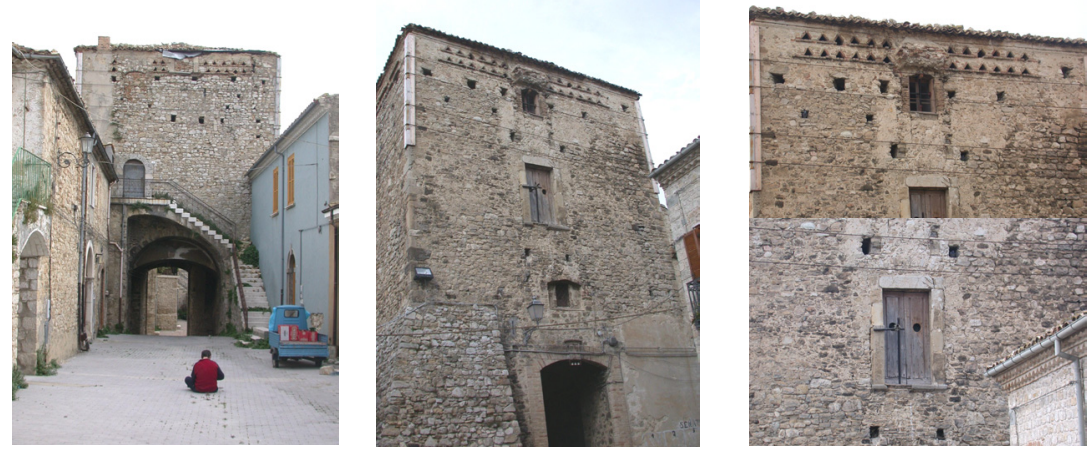

Figure 4: The old Marchesale Castle Tower.

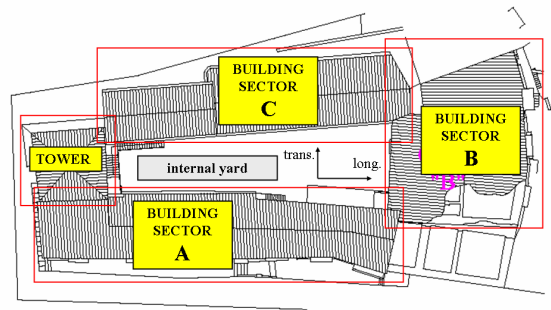

Figure 5: Building sectors characterized during the dynamic tests.

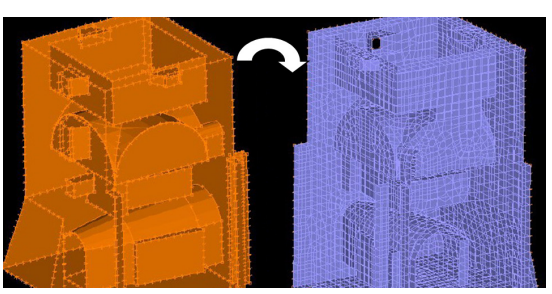

Figure 6: FEM implementation from geometric survey data.

\section{The diagnostics campaign}

A detailed description of the work managed on Marchesale Castle is given in [12]. Flat jack tests measured local compression $\left(1.0 \sim 4.0 \mathrm{~kg} / \mathrm{cm}^{2}\right)$ and Elasticity Modulus $(2000 \sim 3500 \mathrm{MPa})$; the compressive resistance can be estimated around a value of $15.0 \sim 20.0 \mathrm{~kg} / \mathrm{cm}^{2}$. Shear pull-out tests (generally done in the same positions of the flat jack tests in order to correlate masonry sliding properties with local axial compression) gave values around $2.0 \sim 3.5 \mathrm{~kg} / \mathrm{cm}^{2}$. Borehole coring with video endoscopy tests (performed on 
elevation and foundation walls with particular attention to the tower) showed, in most cases, a poor internal core (small stones, lack of mortar and voids presence). Sonic pulse velocity tests detected the presence of voids, cracks and damage patterns.

\section{The dynamic campaign}

Ambient vibration tests [3] have been carried out in order to characterize various castle sectors (fig. 5). For sector A, a modal shape $(5.8 \mathrm{~Hz})$ has been identified in the transversal direction; another peak $(4.5 \mathrm{~Hz})$ is probably due to the presence of the adjacent tower. In the longitudinal direction, a frequency of $10.7 \mathrm{~Hz}$ has been detected, but also less evident peaks $(8.0$ and $8.8 \mathrm{~Hz}$ ). For sector B, a frequency of $5.8 \mathrm{~Hz}$ has been noted in the transversal direction (maybe a torsion mode, thanks to crossed lectures of the sensors data); another value $(4.5 \mathrm{~Hz})$ seemed of translational nature. In the longitudinal direction, frequencies of about 6.0 and $8.5 \mathrm{~Hz}$ have been found, but also other peaks between 10 and $15 \mathrm{~Hz}$. The tower behaviour is clear: two main frequencies $(4.5 \mathrm{~Hz}$ transversal and $5.1 \mathrm{~Hz}$ longitudinal) seemed both bending modes; a third value $(7.5 \mathrm{~Hz})$ is probably associated to torsion.

\section{Numerical models}

The use of Finite Element Models (FEMs) for MCUHESs, implemented by data coming from tests, can be helpful to understand static/dynamic behavior, identify modal frequencies, evaluate stress/strain, displacement and acceleration, verify safety margins and quantify strengthening effectiveness. Tower preliminary FEMs were implemented [15] and then developed [4]. Structural analyses have been carried out by using two different models: a "general purpose" FEM (ADINA [2]) and a specific code for masonry structures (3Muri [14]), through a frame with macro-elements and equivalent horizontal floors.

\subsection{ADINA model}

The FEM has been implemented by a direct transformation of the CAD geometric survey drawings, taking into account structural irregularities and morphological details (fig. 6). A mesh density optimization balanced accuracy and calculation time; the best FEM is characterized by an intermediate topology (14567 nodes and 20585 3D solid elements). The masonry characteristics have been identified not only considering code prescriptions and investigation results, but also a fitting on the experimental frequencies (table 1). An intermediate Confidence Factor (1.20) has been selected, depending on the construction knowledge level (ranging from 1.00, exhaustive, to 1.35, limited). The "Importance Factors" $\gamma_{\mathrm{I}}$, used for loads combinations to increase the seismic demand in case of particular importance buildings, are fixed in the seismic code [16] but redefined for cultural heritage in [17], according to artistic relevance and final destination [13]. In our case, $\gamma_{\mathrm{I}}$ has been taken equal to 1.0. For the limit 
state analyses, the elastic and design spectra definition followed again the code requirements (see tables 2-3 and fig. 7). In masonry aggregates, the reciprocal interactions must be carefully evaluated; therefore, constraint and contour conditions have been calibrated, generating the following tower base-fixed FEMs (fig. 8): (i) non-interacting with adjacent buildings; (ii) interacting with adjacent buildings, with rigid constraints in correspondence of the contact walls; (iii) interacting with adjacent buildings, simulating a portion of the contact walls with more flexible constraints, in order to consider the structural deformability; (iv) equal to the latter, but adding constraints simulating steel ties at the roof level, to inhibit relative displacements at the nodes. Several sets of calculations have been carried out (linear static analysis under vertical and horizontal loads, modal and response spectrum analysis).

Table 1: $\quad$ Material parameters used in the FEMs.

\begin{tabular}{|c|c|c|c|c|c|}
\hline \multicolumn{7}{|c|}{ (a) code prescriptions } \\
\hline material & $\begin{array}{c}\mathrm{E} \\
{\left[\mathrm{N} / \mathrm{mm}^{2}\right]}\end{array}$ & $\begin{array}{c}\mathrm{G} \\
{\left[\mathrm{N} / \mathrm{mm}^{2}\right]}\end{array}$ & $\begin{array}{c}\text { density } \\
{\left[\mathrm{kN} / \mathrm{m}^{3}\right]}\end{array}$ & $\begin{array}{c}\mathrm{f}_{\mathrm{m}} \\
{\left[\mathrm{N} / \mathrm{cm}^{2}\right]}\end{array}$ & $\begin{array}{c}\text { shear resistance } \\
{\left[\mathrm{N} / \mathrm{cm}^{2}\right]}\end{array}$ \\
\hline ordinary masonry & 1230 & 205 & 20 & 132.50 & 4.30 \\
\hline (b) parameters after the fitting on the experimental frequencies \\
\hline
\end{tabular}

Table 2: $\quad$ Italian seismic code expressions for the elastic response spectra.

\begin{tabular}{|c|c|c|c|c|c|c|c|c|}
\hline \multicolumn{9}{|c|}{ horizontal acceleration } \\
\hline $0 \leq \mathrm{T}<\mathrm{T}_{\mathrm{B}}$ & \multicolumn{8}{|c|}{$\mathrm{S}_{\mathrm{e}}(\mathrm{T})=\mathrm{a}_{\mathrm{g}} \cdot \mathrm{S} \cdot\left\{1+\mathrm{T} / \mathrm{T}_{\mathrm{B}} \cdot\left(\eta \cdot \beta_{0}-1\right)\right\}$} \\
\hline $\mathrm{T}_{\mathrm{B}} \leq \mathrm{T}<\mathrm{T}_{\mathrm{C}}$ & \multicolumn{8}{|c|}{$\mathrm{S}_{\mathrm{e}}(\mathrm{T})=\mathrm{a}_{\mathrm{g}} \cdot \mathrm{S} \cdot \eta \cdot \beta_{0}$} \\
\hline $\mathrm{T}_{\mathrm{C}} \leq \mathrm{T}<\mathrm{T}_{\mathrm{D}}$ & \multicolumn{8}{|c|}{$\mathrm{S}_{\mathrm{e}}(\mathrm{T})=\mathrm{a}_{\mathrm{g}} \cdot \mathrm{S} \cdot \eta \cdot \beta_{0} \cdot\left(\mathrm{T}_{\mathrm{C}} / \mathrm{T}\right)$} \\
\hline $\mathrm{T}_{\mathrm{D}} \leq \mathrm{T}$ & \multicolumn{8}{|c|}{$S_{e}(T)=a_{g} \cdot S \cdot \eta \cdot \beta_{0} \cdot\left(T_{C} T_{D} / T^{2}\right)$} \\
\hline soil category & $\mathrm{a}_{\mathrm{g}}$ & $\mathrm{S}$ & $\mathrm{T}_{\mathrm{B}}$ & $\mathrm{T}_{\mathrm{C}}$ & $\mathrm{T}_{\mathrm{D}}$ & $\beta_{0}$ & $\eta$ & $\xi$ \\
\hline A (rock) & 0.25 & 1.00 & 0.15 & 0.40 & 2.00 & 2.50 & 1.00 & 5.00 \\
\hline \multicolumn{9}{|c|}{ vertical acceleration } \\
\hline $0 \leq \mathrm{T}<\mathrm{T}_{\mathrm{B}}$ & \multirow{2}{*}{\multicolumn{8}{|c|}{$\begin{array}{r}S_{v e}(T)=0.9 \cdot a_{g} \cdot S \cdot\left\{1+T / T_{B} \cdot\left(\eta \cdot \beta_{0}\right.\right. \\
S_{v e}(T)=0.9 \cdot a_{r} \cdot S \cdot \eta \cdot \beta_{0}\end{array}$}} \\
\hline $\mathrm{T}_{\mathrm{B}} \leq \mathrm{T}<\mathrm{T}_{\mathrm{C}}$ & & & & & & & & \\
\hline $\mathrm{T}_{\mathrm{C}} \leq \mathrm{T}<\mathrm{T}_{\mathrm{D}}$ & \multicolumn{8}{|c|}{$\mathrm{S}_{\mathrm{ve}}(\mathrm{T})=0.9 \cdot \mathrm{a}_{\mathrm{g}} \cdot \mathrm{S} \cdot \eta \cdot \beta_{0} \cdot\left(\mathrm{T}_{\mathrm{C}} / \mathrm{T}\right)$} \\
\hline $\mathrm{T}_{\mathrm{D}} \leq \mathrm{T}$ & \multicolumn{8}{|c|}{$\mathrm{S}_{\mathrm{ve}}(\mathrm{T})=0.9 \cdot \mathrm{a}_{\mathrm{g}} \cdot \mathrm{S} \cdot \eta \cdot \beta_{0} \cdot\left(\mathrm{T}_{\mathrm{C}} \mathrm{T}_{\mathrm{D}} / \mathrm{T}^{2}\right)$} \\
\hline soil category & $\mathrm{a}_{\mathrm{g}}$ & $\mathrm{S}$ & $\mathrm{T}_{\mathrm{B}}$ & $\mathrm{T}_{\mathrm{C}}$ & $\mathrm{T}_{\mathrm{D}}$ & $\beta_{0}$ & $\eta$ & $\xi$ \\
\hline A (rock) & & 1.00 & 0.05 & 0.15 & 1.00 & 3.00 & 1.00 & 5.00 \\
\hline
\end{tabular}

Table 3: $\quad$ Italian seismic code values for the design response spectra.

\begin{tabular}{|c|c|}
\hline Confidence Factor CF (medium-high knowledge level) & 1.2 \\
\hline Importance Factor $\gamma_{\mathrm{I}}$ & 1.0 \\
\hline ordinary masonry buildings not regular in height & $\mathrm{q}=\mathrm{q}_{0} \alpha_{\mathrm{u}} / \alpha_{1}$ \\
\hline $\mathrm{q}_{0}=1.5$ & $\mathrm{q}_{0} / \alpha_{1}=1.8$ \\
\hline Structure Factor for the Ultimate Limit State $\mathrm{q}_{\mathrm{ULS}}$ & $\mathrm{q}=2.7$ \\
\hline Structure Factor for the Damage Limit State $\mathrm{q}_{\mathrm{DLS}}$ & 2.5 \\
\hline
\end{tabular}



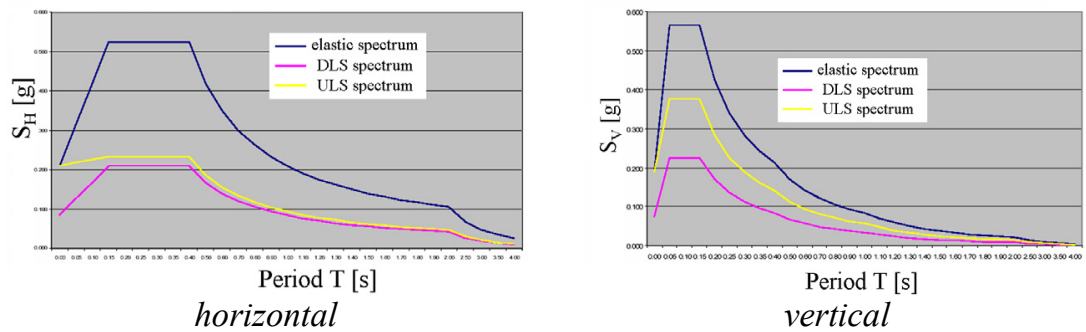

Figure 7: $\quad$ Elastic and design spectra.

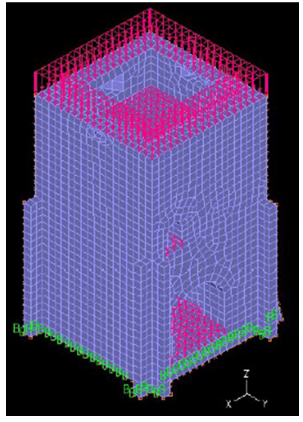

no

constraints

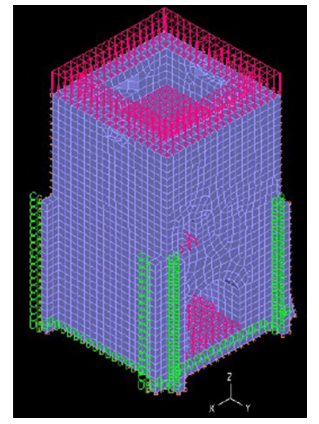

rigid or flexible constraints

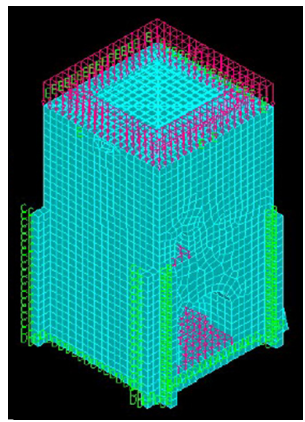

flexible constraints and steel ties at the roof level

Figure 8: $\quad$ FEMs with different constraint and contour conditions.

Table 4: $\quad$ Displacement values for linear static analysis.

\begin{tabular}{|c|c|c|c|c|}
\hline $\begin{array}{c}\text { linear static analysis displacement under vertical loads } \\
\text { FEM (iii) [mm] }\end{array}$ & $\mathrm{u}$ & $\mathrm{x}$ & $\mathrm{y}$ & $\mathrm{z}$ \\
\hline max. & 1.70 & 0.50 & 0.30 & 0.00 \\
\hline min. & 0.00 & 0.00 & 0.00 & 1.70 \\
\hline $\begin{array}{c}\text { linear static analysis displacement under horizontal loads } \\
\text { FEM (iii) [mm] - x direction }\end{array}$ & $\mathrm{u}$ & $\mathrm{x}$ & $\mathrm{y}$ & $\mathrm{z}$ \\
\hline max. & 6.70 & 6.37 & 3.68 & 0.60 \\
\hline min. & & & 3.03 & -3.07 \\
\hline $\begin{array}{c}\text { linear static analysis displacement under horizontal loads } \\
\text { FEM (iv) [mm] -y direction }\end{array}$ & $\mathrm{u}$ & $\mathrm{x}$ & $\mathrm{y}$ & $\mathrm{z}$ \\
\hline max. & 6.77 & 0.89 & 6.01 & 0.78 \\
\hline min. & & -2.92 & & -3.19 \\
\hline
\end{tabular}

Table 4 shows the calculated displacements for linear elastic analysis: in case of horizontal loads, the force distribution has been taken first mode proportional. Table 5 shows the first ten frequencies. Although a linear elastic behaviour (which is non-realistic) has been assumed in the calculations for the masonry, nevertheless the results provide interesting information on deformation and damage mechanisms. The earthquake damage subjected by the tower seems to be well described by the calculated modal shapes (modes 1 and 2 bending; mode 3 torsion), fitted with the experimental data (fig. 9 and table 5). 
Table 5: $\quad$ Natural frequencies obtained for FEMs (iii) and (iv).

\begin{tabular}{|c|c|c|c|c|c|c|c|}
\hline \multirow[t]{2}{*}{$\begin{array}{c}\text { natural } \\
\text { frequencies }\end{array}$} & (iii) & (iv) & exp. & $\begin{array}{c}\text { natural } \\
\text { frequencies }\end{array}$ & (iii) & (iv) & exp. \\
\hline & \multicolumn{3}{|c|}{$\overline{[\mathrm{Hz}]}$} & & \multicolumn{3}{|c|}{$[\mathrm{Hz}]$} \\
\hline mode 01 & 4.810 & 4.811 & 4.500 & mode 06 & 12.061 & 12.067 & - \\
\hline mode 02 & 4.927 & 4.930 & 5.700 & mode 07 & 12.520 & 13.605 & - \\
\hline mode 03 & 8.673 & 8.674 & 7.500 & mode 08 & 13.602 & 16.529 & - \\
\hline mode 04 & 10.855 & 10.868 & - & mode 09 & 16.356 & 16.620 & - \\
\hline mode 05 & 11.700 & 11.704 & - & mode 10 & 16.439 & 18.809 & - \\
\hline
\end{tabular}

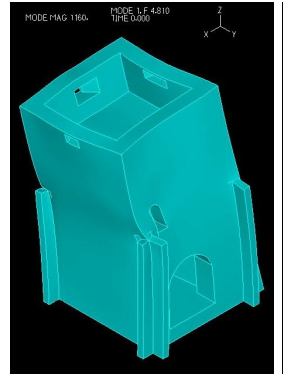

mode 1

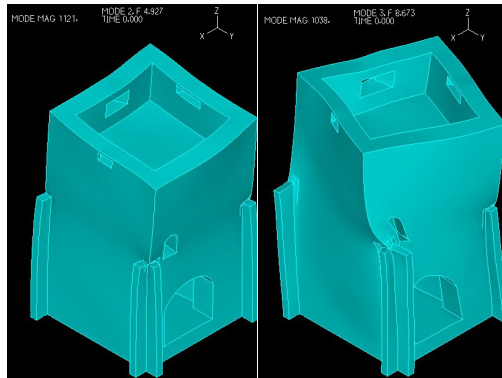

mode 2 mode 3

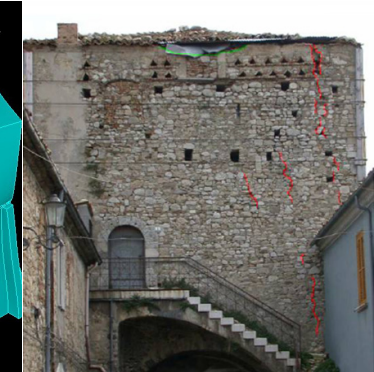

earthquake damage

Figure 9: Calculated modal shapes and tower earthquake damage.

\subsection{Muri model}

Also in this case, several models of the tower have been implemented: base-fixed with (j) and without (jj) interactions to adjacent buildings; base-fixed with (jjj) and without (jv) masonry improvement through mortar injections. The tower vertical components have been schematized through macro-elements (rigid nodes, openings, masonry belts, vertical walls), while the horizontal ones described by floor elements with infinite axial stiffness and no bending.

Push-over analyses have been done, taking into account 24 cases deriving from the load type combinations (mass proportional or first mode proportional), direction of the seismic action and load eccentricity, with the aim of identifying the most dangerous scenario. For each load case considered, safety margins have been verified, as requested by the Italian seismic code. In models (j) and (jj), a sudden collapse happens at the building base; it is due to the great stiffness of the masonry walls at this level, as showed by the push-over curve, missing the descendent branch (fig. 10). On the contrary, in models (jij) and (jv), damage happens in the masonry walls placed over the constraints representing the confining effect due to the presence of adjacent buildings. Being these walls thinner than the basement, the non-sudden collapse derives from the macroelements plasticization (fig. 11). It is worth noting that in models (jjj) and (jv) the code required performance is verified, coherently with the features of the push-over analyses. These analyses can well represent the global behaviour of the building under the effect of horizontal actions, but local damage due to 
shaking effects can be lost. As a matter of fact, the Italian code foresees also the analysis of local damage mechanisms, regarding out-of-plane collapse of single panels and overturning of entire vertical walls (if monolithic), as shown by many earthquake damage patterns. In conclusion, the structural designer must know different capabilities and limits of various methods.
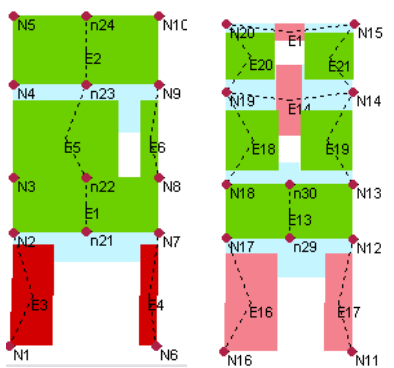

0.P.C.M. 3274 : Verifica SLU NON soddisfatta - Verifica SLD NON soddisfatta $Y[$ [all]

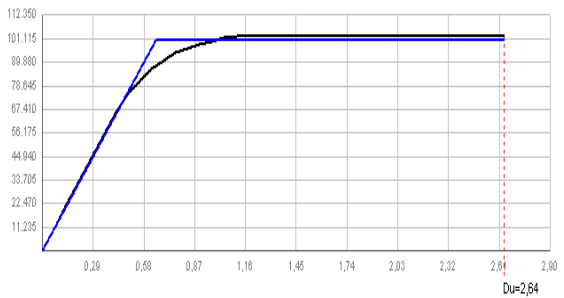

Figure 10: Models (j) and (jj), collapse mechanism and push-over curve.
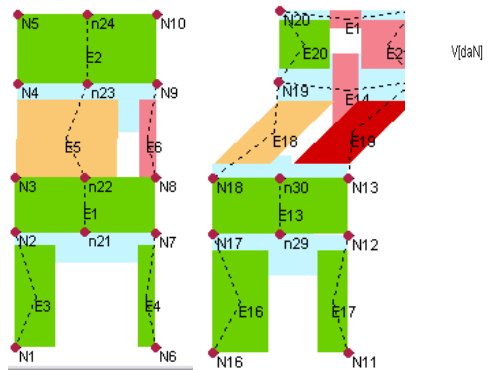

0.P.C.M. 3274 : Verifica SLU soddlisfatta - Verifica SLD soddisfatta

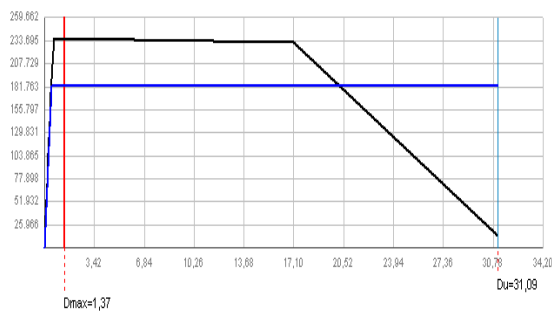

Figure 11: Models (jjj) and (jv), collapse mechanism and push-over curve.

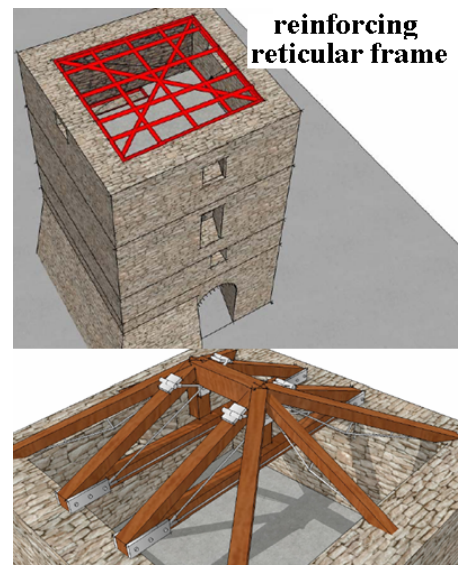

Figure 12: Tower roof strengthening. 


\section{The rehabilitation design of Marchesale Castle}

Thanks to experimental/numerical data, an antiseismic improvement proposal has been suggested, to harmonize protection and conservation, in agreement with the codes. Vertical walls strengthening (and their reciprocal interconnections) is recommended, throughout the insertion of steel-ties at each level (using, if possible, innovative materials as shape memory alloy devices [1]), in both the horizontal directions, together with a limited reconstruction of the most damaged masonry portions by using similar and compatible materials, avoiding local stiffening. Injections of compatible mortar, where necessary, have to be done after a detailed identification of mixtures and procedures. Only if indispensable, the "a sacco" masonry can be strengthened by the insertion of transversal connections, with the aim of linking the external wall sheets with each other. Vaults reinforcing has to be carried out by using conventional methods (repairing and thickening by layers of thin bricks), but rejecting r.c. coping. All the floors should be light enough, preferably wooden made, but provided by adequate stiffness (using cross-bracing systems and additional wood planking), anchoring them carefully to the vertical walls, keeping off the use of floor r.c. stringcourses and preferring steel string-courses; at the roof level (fig. 12), a reinforced masonry-course (or reticular frame steel string-course or wood string-course) can be provided, together with effective connections of the wooden roof components.

\section{Conclusions}

The work suggests strengthening interventions for the Marchesale Castle old masonry tower, damaged by the 2003 earthquake, after discussing experimental and numerical results. It is possible to give the structure its original stiffness and place resistant systems capable of improving the building dynamic response to seismic shear-force actions (according to the existing set of rules), respecting the original structure as much as possible, and avoiding conflicts between conservation criteria and antiseismic requirements.

\section{References}

[1] Auricchio F. et al. (eds), Shape Memory Alloys. Advances in modelling and applications. CIMNE ed. Barcellona, Spain, 2001, ISBN 84-8992582-8.

[2] Bathe K.J., ADINA, http://www.adina.com/, 1986.

[3] Buffarini G. et al. Rilievo delle vibrazioni ambientali di Palazzo Marchesale a San Giuliano di Puglia (CB). ENEA Report, 2006.

[4] Cami R., Tecniche antisismiche moderne e metodi di calcolo strutturale per la protezione dei beni storico monumentali: il caso della torre di Palazzo Marchesale a San Giuliano di Puglia. Ph.D. Thesis, University of Ferrara, Faculty of Engineering. Tutors: Tralli A. and Indirli M., 2007. 
[5] Carpani B., Indirli M., Commenti sul progetto esecutivo di consolidamento statico e di riqualificazione funzionale del Palazzo Marchesale situato a San Giuliano di Puglia (CB). ENEA Report, 2005.

[6] Doglioni F. et al., Le chiese e il terremoto, LINT: Trieste, 1994.

[7] Doglioni F., Codice di Pratica per la progettazione degli interventi di riparazione, miglioramento sismico e restauro dei Beni Architettonici danneggiati dal terremoto umbro-marchigiano del 1997. Bollettino Ufficiale Regione Marche n. 15, 2000.

[8] Giuffrè A., Monumenti e terremoti. Multigrafica Editrice: Roma, 1988.

[9] Giuffrè A., Sicurezza e conservazione dei centri storici. Il caso di Ortigia. Laterza: Bari, 1993.

[10] Indirli, M. et al., The reconstruction of San Giuliano di Puglia after the October $31^{\text {st }} 2002$ earthquake. Proc. $13^{\text {th }}$ World Conference on Earthquake Engineering, August 2004, Vancouver, B.C., Canada.

[11] Indirli M. et al., Seismic protection of historical centers using innovative techniques, with focus on San Giuliano di Puglia after the 2002 Molise earthquake. Proc. IV SAHC International Conference, November 2004, Padua, Italy.

[12] Indirli M. et al., The antiseismic rehabilitation of Marchesale Castle at San Giuliano di Puglia, Proc. IV SAHC International Conference, November 2006, New Delhi, India.

[13] Modena C. et al., Codes of Practice for Architectural Heritage in Seismic Zones, Proc. of the V International Conference on Structural Analysis of Historical Constructions (SAHC), November 2006, New Delhi, India, Lourenço P.B., Roca P., Modena C., Agrawal S. (eds).

[14] Lagomarsino S., Penna A., Galasco A., 3Muri, Linear and non-linear static analysis of masonry and mixed buildings, http://www.stadata.com, 2005.

[15] Pistola F., "Protezione dai terremoti con tecniche innovative, con particolare riferimento al patrimonio culturale: il caso di San Giuliano di Puglia". Degree Thesis, University of Florence, Faculty of Architecture, Tutors: Prof. Briccoli Bati S., Indirli M. and Cami R., 2005.

[16] Presidenza del Consiglio dei Ministri, OPCM 3274, 3316, 3431, Gazzetta Ufficiale: May $8^{\text {th }}, 2003$, Ser. Gen. n. 105, Suppl. Ord. n. 72; October $10^{\text {th }}$, 2003, Ser. Gen. n. 236; May 10 ${ }^{\text {th }}$, 2005, Ser. Gen. n. 107, Suppl. Ord. n. 85.

[17] Presidenza del Consiglio dei Ministri, Linee Guida per l'applicazione al patrimonio culturale della normativa tecnica, 2006. 